Abstracta Iranica Abstracta Iranica

Revue bibliographique pour le domaine irano-aryen

Volume 34-35-36 | 2017

Comptes rendus des publications de 2011-2013

\title{
Lori Khatchadourian. An archaeology of Hegemony. The Achaemenid empire and the remaking of the fortress in the Armenian highlands
}

\section{Sébastien Gondet}

\section{(2) OpenEdition}

Journals

Édition électronique

URL : http://journals.openedition.org/abstractairanica/42118

DOI : $10.4000 /$ abstractairanica.42118

ISSN : 1961-960X

Éditeur :

CNRS (UMR 7528 Mondes iraniens et indiens), Éditions de l'IFRI

Référence électronique

Sébastien Gondet, «Lori Khatchadourian. An archaeology of Hegemony. The Achaemenid empire and the remaking of the fortress in the Armenian highlands », Abstracta Iranica [En ligne], Volume 34-35-36 | 2017, document 114, mis en ligne le 30 juillet 2017, consulté le 05 octobre 2020. URL : http://

journals.openedition.org/abstractairanica/42118; DOI : https://doi.org/10.4000/abstractairanica. 42118

Ce document a été généré automatiquement le 5 octobre 2020.

Tous droits réservés 


\section{Lori Khatchadourian. An archaeology of Hegemony. The Achaemenid empire and the remaking of the fortress in the Armenian highlands}

Sébastien Gondet

\section{RÉFÉRENCE}

Lori Khatchadourian. "An archaeology of Hegemony. The Achaemenid empire and the remaking of the fortress in the Armenian highlands ", in: G. E. Areshian, ed., Empires and Diversity: on the Crossroads of Archaeology, Anthropology and History. Los Angeles, Cotsen Institute of Archaeology Press, 2013, p. 108-145. (Ideas, Debates, and Perspectives 7)

1 L'A. se place très clairement dans la perspective d'un empire achéménide exerçant une mainmise forte sur les territoires placés sous son contrôle. Une analyse de l'occupation achéménide de la province d'Arménie apporterait des preuves de cette volonté hégémonique. Au cours de la période achéménide, contrairement à l'idée souvent véhiculée selon laquelle les forteresses urartéennes auraient toutes été abandonnées, les sites d'Erebuni et d'Altintepe continuent de constituer des centres de pouvoir locaux importants. Les grandes salles à colonnes présentes sur ces deux sites constitueraient les témoins matériels de la présence d'une élite perse et même l'espace matriciel de la production d'une classe dominante locale persianisée. L'empreinte achéménide en Arménie serait donc marquée par une réorganisation de l'espace de certains des lieux de pouvoir préexistants.

Une grande partie de l'article s'attache à reconsidérer la chronologie de ces grandes salles hypostyles. L'A. discute dans le détail la proposition de D. Stronach de dater la fondation de la grande salle à colonnes d'Erebuni de la première moitié du $\mathrm{VI}^{\mathrm{e}} \mathrm{s}$. av. J.- 
C. (Voir c.r. $n^{\circ} 111$ de cette même rubrique 3-2-2 et AI-Vol.32-33-Rub.3-2-2-n.120). Pour sa part, elle n'exclue pas une construction de date achéménide et la réorganisation de la forteresse constituerait une preuve directe d'une intervention du nouveau pouvoir. Si la salle était pré-achéménide, elle aurait été conservée et utilisée par la cour en place car elle entrait en résonnance avec la création d'espaces monumentaux pour la classe dirigeante et servait sa propagande officielle.

3 Les évolutions observées en Arménie sont en phase avec le développement de centres royaux où le bâti monumental s'intègre à des plans très ouverts à Pasargades, Suse ou Persépolis. Les plans des forteresses s'ouvrent, intègrent des espaces d'apparat pour la cour et les lieux et activités de la vie quotidienne se seraient déplacés autour des lieux fortifiés sur des hauteurs. Cet article plaide donc en faveur d'une étude à plus large échelle et coordonnée de l'impact achéménide sur l'organisation des grands centres de pouvoir de l'empire.

\section{AUTEURS}

\section{SÉBASTIEN GONDET}

UMR 5133 CNRS-Université de Lyon 